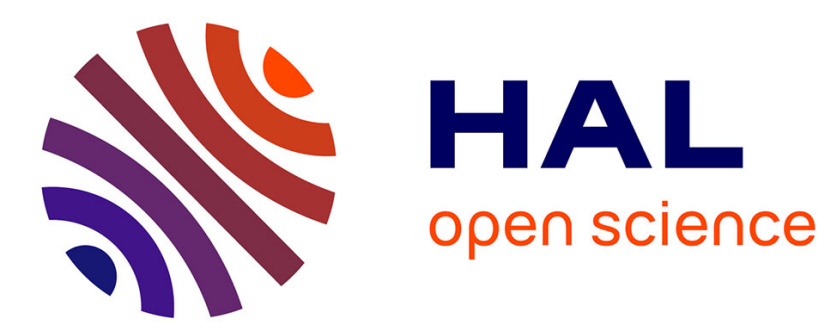

\title{
Valuing lagoons using a meta-analytical approach: methodological and practical issues
}

Geoffroy Enjolras, Jean-Marie Boisson

\section{To cite this version:}

Geoffroy Enjolras, Jean-Marie Boisson. Valuing lagoons using a meta-analytical approach: methodological and practical issues. 2008. hal-02821456

\section{HAL Id: hal-02821456 \\ https://hal.inrae.fr/hal-02821456}

Preprint submitted on 6 Jun 2020

HAL is a multi-disciplinary open access archive for the deposit and dissemination of scientific research documents, whether they are published or not. The documents may come from teaching and research institutions in France or abroad, or from public or private research centers.
L'archive ouverte pluridisciplinaire HAL, est destinée au dépôt et à la diffusion de documents scientifiques de niveau recherche, publiés ou non, émanant des établissements d'enseignement et de recherche français ou étrangers, des laboratoires publics ou privés. 


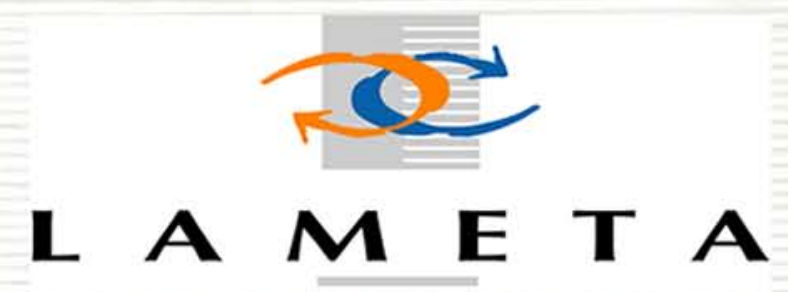

Laboratoire Montpelliérain d'Economie Théorique et Appliquée

\section{U M R}

Unité Mixte de Recherche

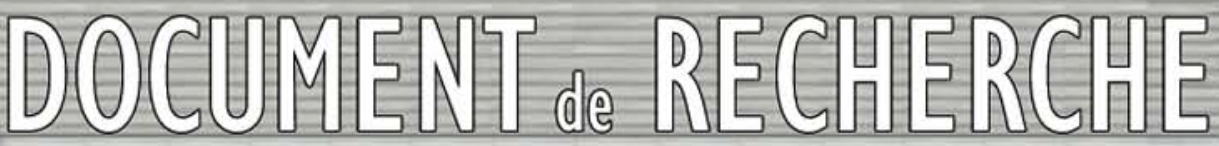

$\ll$ Valuing lagoons using a meta-

analytical approach : Methodological and

practical issues »

Geoffroy ENJOLRAS

Jean-Marie BOISSON

DR n²008-05

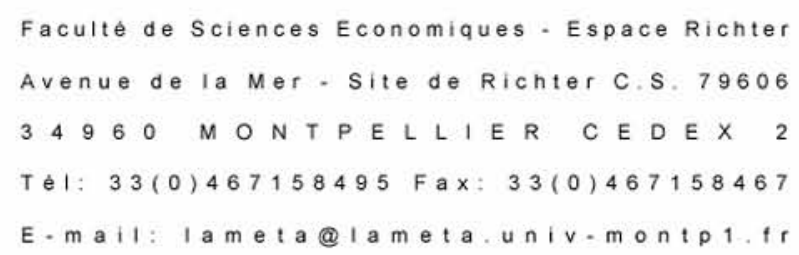




\title{
Valuing lagoons using a meta-analytical approach: Methodological and practical issues
}

\author{
Geoffroy Enjolras ` Jean-Marie Boisson ^
}

\begin{abstract}
April, 2008

\section{Abstract}

Among coastal areas, lagoons are probably one of the most active and sensitive areas. They provide numerous goods and services that are of value to people. As public goods, there are freely accessible but in counterpart there are more endangered than other areas. Conflict uses between activities inside and outside the lagoons or between occasional and regular users imply to implement the lagoons economic values in order to provide a useful management tool. Many studies have been driven in order to estimate the impacts of the different activities on water quality and the willingness to pay for a better environment. We collect 32 lagoon studies providing 67 value observations in order to present a comprehensive meta-analysis of the valuation literature. This method allows estimating a function that takes into account the sites characteristics, methodological variables and lagoons services. The estimation of a metaanalytic function proves that all theses kinds of variables are important for the calculus of values. Moreover, we precisely determine the influence of the different variables on the value. Performing the transfer, we find an average transfer error amount equal to $87 \%$ but a median transfer error equal to $24 \%$. This result due to a very small number of aberrant values is interesting with one-fourth of the transfers showing errors lower to $10 \%$ and nearly threefourth of the transfers present errors lower to $50 \%$.
\end{abstract}

Note: This research has been realized within the framework of the European DITTY Project (Development of an Information Technology Tool for the Management of European Southern Lagoons under the of Influence of River-Basin Runoff).

JEL numbers: C53, D62, H23, Q20, Q25, Q51

Keywords: Meta-analysis, valuation, value transfer, lagoons, ecosystems functions

\section{Introduction}

Lagoons cover two main realities. Firstly, they are part of coastal areas whose development increases over the years and all over the world. Secondly, they are often considered as a category of wetlands, which includes both mangroves and marshes. As public goods, there are freely accessible and exploited but in counterpart there are more endangered than other areas. Thus, there is a real need for studies focused on the economic valuation of lagoons. In this field, numerous valuation studies about lagoons have been implemented since the sixties and for the first time, we propose a meta-analysis focused on this subject.

\footnotetext{
- PhD Student and Teaching Assistant, University of Montpellier 1

LAMETA - INRA, 2 place Pierre Viala, 34060 Montpellier Cedex 1, France

Mail: enjolras@ensam.inra.fr, corresponding author

$\diamond$ Professor, University of Montpellier 1

LAMETA - UFR Sciences Economiques, Avenue de la Mer, CS 79606, 34960 Montpellier Cedex 2, France

Mail: jean-marie.boisson@univ-montp1.fr
} 
The potentialities of valuations transfer have been highlighted since 1992 when Water Resources Research published the first special research and commentary section dedicated to benefit transfer (Volume 28, Issue 3). In December 2006, Ecological Economics proposed to summarize the state-of-the-art of environmental benefit transfer and to assist in the design and reporting of future benefit estimation research (Volume 60, Issue 2, Pages 335-482).

The principle of this method, as one knows, is to transfer existing results determined on "study sites", at one moment and in a given context, to other sites, called "policy sites", when their characteristics are quite close. This is the principle of the benefits or valuations transfer. This method is empirical and pragmatic and, in any way, cheaper for the economic valuation of many environmental goods. Indeed, it gives the opportunity to estimate benefits or at least obtain an approximate idea of them. It avoids performing complete studies, which generates substantial economies in time and financial resources. Of course, they demand rigorous procedures and know some limits.

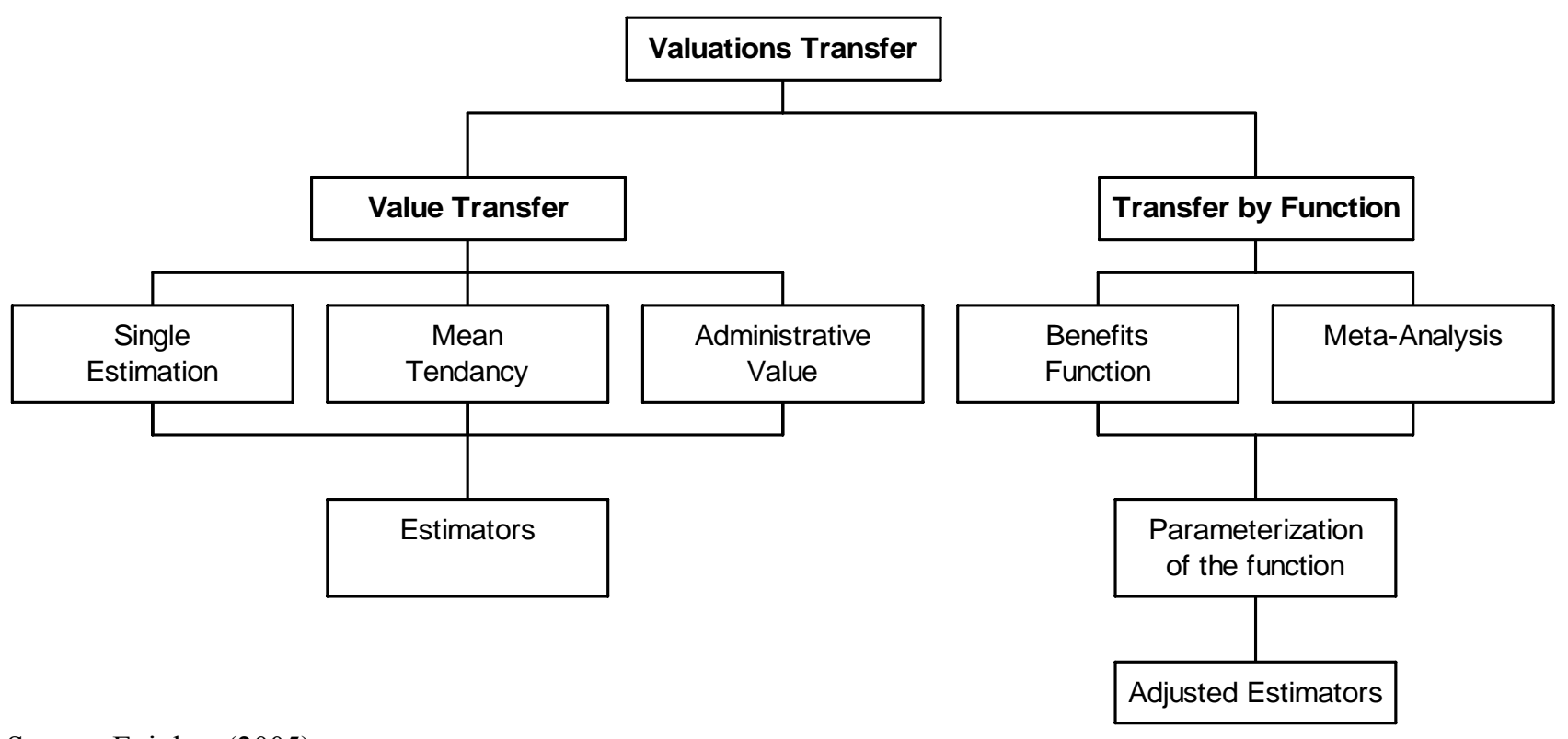

Source: Enjolras (2005).

\section{Figure 1 - The different ways to perform a Valuations Transfer}

Figure 1 exposes the different types of transfer. To take into account lagoon particularities, it is better to transfer not values, but an economic function estimated on the results obtained for one or a group of lagoons, in a meta-analysis. Classically, the model explains the value of water with a function of specific variables linked to the lagoon (physical characteristics, activities, etc.) and to the resident population (socio-economic variables, sensitivity to the environment, etc.). Many authors (Brouwer and Spaninks, 1999; Brouwer, 2000; Shrestha and Loomis, 2003) have showed that this method gives more reliable results because the transferred equation is parameterised according to the characteristics of the "policy site". However, the transfer is not always possible if this function includes contextual variables that are difficult to find or even compute on the policy site, e.g. the stochastic wind-sensitivity of the phenomenon of eutrophication. Moreover, it is necessary to select the transferable studies before performing the application itself: "bad" studies generate "bad" transfers while "rigorous" studies do not systematically generate "good" transfers. 
Three main meta-analysis already exist (Brouwer et al., 1999; Woodward and Wui, 2001; Brander et al., 2006), which are devoted to wetlands in general and examine subsets of the available wetland literature. Brouwer et al. (1999) restrict their analysis to contingent valuation studies. Woodward and Wui (2001) focus on wetlands attributes while Brander et al. (2006) look at all types of wetlands and introduces socio-economic variables in their analysis.

In this article, we propose an international and multivariate meta-analysis focused on lagoons. The first section of the paper is devoted to a general presentation of the lagoons, their nature, functions and values. The second section gathers literature about the economic valuation of lagoons in order to create a synthetic database. The third section presents a multivariate metaanalysis function dedicated to lagoons. The fourth section considers value transfers with our estimated meta-analytic function, validation tests and some remarks and perspectives.

\section{The lagoons: nature, functions and values}

Located at the interface between marine and continental environments, lagoons are often vast littoral wetland areas generally with a low depth and separated from the sea by a strip of land usually named "lido". As natural geomorphic structures contributing to the physical and ecological balance of the whole coast, lagoons play a paramount ecological role. In economic terms, they create externalities. Moreover, the benefits they procure are not included in any market, and thus do not receive any market price valuation.

As it is well known, lagoons take part in the protection of the shores against coastal erosion. Bordering vegetation stabilizes the grounds and thus limits the influence of the marine intrusions, in particular during sea storms. Moreover, each lagoon has often the capacity to absorb the floods of the catchments area and thus protects the residential areas from floods. In addition to this role of regulation of surface volumes of water, wetlands have also the capacity to supply ground water. The diffusion of water through the bottom of the lagoons works like a filter retaining pollutants and nutriments from the water table. From a hydrological point of view, these zones of exchange and transfer of nutritive matters are particularly favourable to the development and the reproduction of vegetable and animal living beings.

However, littorals, especially along the Mediterranean coast, are fragile and highly coveted areas. There are under many various anthropic pressures, which generate more or less reversible ecological disequilibria. Lagoons naturally receive runoff waters, which carry sediments, fertilizers, pesticides and other heavy metals resulting from intensive breeding, agriculture and especially from vineyards and olive trees growing. Since the 1960's, environment modifications are substantial with new tourist establishments (marinas, seaside resorts, roads, etc.) and industrial plants (cooperatives and distilleries refineries, heavy industries, etc.).

As a result, demographic pressure and all its spatial consequences directly contribute to the degradation of the natural environment of the lagoons. The over-frequentation of the sites creates conflicts of use whereas the massive rejections of pollutants are at the origin of anoxia and eutrophication crisis. In repercussion, economic activities in and around the lagoons are affected. Human activities interact with their natural functions, resulting in a deterioration and reduction of the services provided by the aquatic environment. 
Thus, the question is to measure the impact of reducing water quality on economic activities and employment, shellfish farming and fishing, as well as tourism, which are the first affected activities and thus the value of this quality. The following table (Table 2) resumes this point for lagoons.

\begin{tabular}{|c|c|c|c|}
\hline $\begin{array}{c}\text { Ecosystem } \\
\text { structures and } \\
\text { processes that } \\
\text { provide the function }\end{array}$ & Function & $\begin{array}{l}\text { Socio-economic } \\
\text { benefits of the } \\
\text { function }\end{array}$ & $\begin{array}{l}\text { Threats to the } \\
\text { function }\end{array}$ \\
\hline & Hydrological & & \\
\hline $\begin{array}{l}\text { Short- and long-term } \\
\text { storage of over bank } \\
\text { floodwater and detention } \\
\text { of surface water runoff }\end{array}$ & Floodwater retention & $\begin{array}{l}\text { Natural flood protection, } \\
\text { reduced damage to } \\
\text { infrastructure (e.g. roads), } \\
\text { property and crops }\end{array}$ & $\begin{array}{l}\text { Conversion of land use, } \\
\text { drainage, reduction of } \\
\text { storage capacity, removal } \\
\text { of vegetation }\end{array}$ \\
\hline $\begin{array}{l}\text { Infiltration of water into } \\
\text { the ground followed by } \\
\text { percolation to aquifer }\end{array}$ & $\begin{array}{l}\text { Sediment retention and } \\
\text { deposition }\end{array}$ & Water supply & $\begin{array}{l}\text { Reduction in recharge } \\
\text { rates, } \\
\text { pollution }\end{array}$ \\
\hline \multirow[t]{2}{*}{$\begin{array}{l}\text { Retention of sediment } \\
\text { carried in suspension by } \\
\text { water from over bank } \\
\text { flooding or surface runoff }\end{array}$} & $\begin{array}{l}\text { Sediment retention and } \\
\text { deposition }\end{array}$ & $\begin{array}{l}\text { Improved water quality } \\
\text { downstream, increased soil } \\
\text { fertility on site }\end{array}$ & $\begin{array}{l}\text { Channellization, excess } \\
\text { reduction of sediment } \\
\text { throughput }\end{array}$ \\
\hline & Biochemical & & \\
\hline $\begin{array}{l}\text { Uptake of nutrients } \\
\text { (applied as fertilizers) by } \\
\text { plants (nitrogenize and } \\
\text { phosphorus), storage of } \\
\text { nutrients in the soil (as } \\
\text { organic matter and through } \\
\text { absorption) }\end{array}$ & Nutrient retention & Improved water quality & $\begin{array}{l}\text { Removal of vegetation, } \\
\text { cultivation of soil }\end{array}$ \\
\hline \multirow[t]{2}{*}{$\begin{array}{l}\text { Flushing through water } \\
\text { system and gaseous export } \\
\text { of nitrogenize }\end{array}$} & Nutrient export & $\begin{array}{l}\text { Improved water quality, } \\
\text { waste disposal }\end{array}$ & $\begin{array}{l}\text { Removal of vegetation, } \\
\text { flow barriers }\end{array}$ \\
\hline & Ecological & & \\
\hline $\begin{array}{l}\text { Provision of sites for } \\
\text { invertebrates, fish, reptiles, } \\
\text { birds, mammals and } \\
\text { landscape } \\
\text { diversity }\end{array}$ & $\begin{array}{l}\text { Habitats for } \\
\text { (biodiversity) }\end{array}$ & $\begin{array}{l}\text { Fishing, } \\
\text { recreational } \\
\text { tourism }\end{array}$ & $\begin{array}{l}\text { Overexploitation, } \\
\text { overcrowding and } \\
\text { congestion, disturbance of } \\
\text { wildlife pollution, } \\
\text { inadequate management } \\
\end{array}$ \\
\hline $\begin{array}{l}\text { Biomass production, } \\
\text { biomass import and export } \\
\text { via physical and biological } \\
\text { processes }\end{array}$ & Food web support & Agricultural production & $\begin{array}{l}\text { Conversion of land use, } \\
\text { excessive use of inputs } \\
\text { (pollution) }\end{array}$ \\
\hline
\end{tabular}

Adapted from: FAO (2004).

\section{$\underline{\text { Table } 2 \text { - A selection of lagoon ecosystem functions and associated socio-economic benefits }}$}

Apart from the traditional definition of the economic value, which lies on the actual or potential use of a good or service, one must take into account in the case of the environment some kind of value, which is not linked, with an effective or potential use of the good. This is the case for example of value attached to the possibility for a future generation to use the good as a bequest of the present generation, or even more simply, the value one attaches to the mere existence of a natural good or even a special sort of threatened living being. 
The different kinds of economic water valuation in this broadened perspective can be summarised in the following figure adapted from Pearce and Markandya (1989):

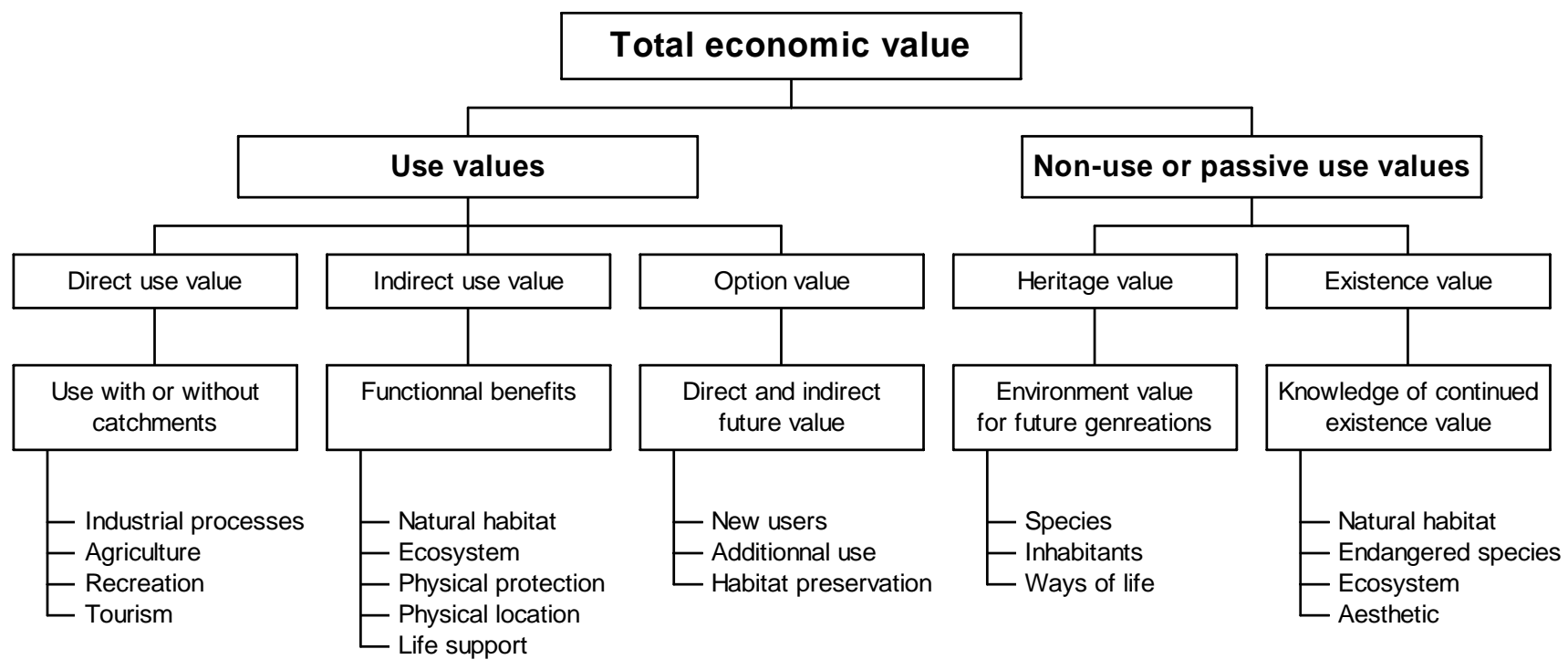

Figure 3-Economic values to be transferred

Among use values, we usually distinguish:

- Direct use, which comes from direct catchment or interaction with the environmental resources and services.

- Indirect use of an ecological function, which is linked to a change in production or consumption values.

- Option values, which are the willingness to pay for preserving a good/service for future use, e.g. biodiversity preservation. Quasi-option value is a measure of social wealthare linked to a future improvement of available information.

Non-use or passive use are of course very difficult to measure with accuracy. They cover the following aspects:

- Heritage value comes from a common will to leave natural resources and a certain environment quality to future generations.

- Existence value reflects a will to preserve an environmental asset for its intrinsic value. 
Applied to lagoons, this methodology permits to draw up the following table.

\begin{tabular}{|l|l|l|l|}
\hline \multicolumn{1}{|c|}{ Ecological function } & \multicolumn{1}{|c|}{ Economic goods and services } & \multicolumn{1}{|c|}{ Value type } & \multicolumn{1}{c|}{$\begin{array}{c}\text { Commonly used } \\
\text { valuation methods }\end{array}$} \\
\hline Flood and flow control & Flood protection & Indirect use & RC, MP, OC \\
\hline Storm buffering & Storm protection & Indirect use & RC, PF \\
\hline Sediments retention & Storm protection & Indirect use & RC, PF \\
\hline $\begin{array}{l}\text { Groundwater recharge } \\
\text { or discharge }\end{array}$ & Water supply & Indirect use & RC, PF, NFI \\
\hline $\begin{array}{l}\text { Water quality } \\
\text { maintenance } \\
\text { Nutrient retention }\end{array}$ & Improved water quality & Indirect use & CVM \\
\cline { 2 - 4 } $\begin{array}{l}\text { Habitat and nursery for } \\
\text { plants and animal } \\
\text { species }\end{array}$ & Raste disposal & Direct use & RC \\
\cline { 2 - 4 } & Commercial fishing and hunting & Direct use & MP, NFI \\
\cline { 2 - 5 } & Harvesting of natural materials & Direct use & TCM, CVM \\
\cline { 2 - 5 } Biological diversity & Energy resources & MP \\
\hline $\begin{array}{l}\text { Micro-climate } \\
\text { stabilization }\end{array}$ & Appreciation of species existence & Direct use & MP \\
\hline Carbon sequestration & Climate stabilization & Reduced global warming & CVM \\
\hline \multirow{3}{*}{ Natural environment } & Amenity & Indirect use & RC \\
\cline { 2 - 5 } & Recreational activities & Direct use & HP, CVM \\
\cline { 2 - 5 } & $\begin{array}{l}\text { Appreciation of uniqueness to culture } \\
\text { and heritage }\end{array}$ & Direct use & CVM, TCM \\
\hline
\end{tabular}

Source: with modifications adapted from Barbier (1991, 1997), Brouwer et al. (1999), Woodward and Wui (2001) and Brander et al. (2006).

Acronyms refer to replacement cost (RC), market prices (MP), opportunity costs (OC), net factor income (NFI), the contingent valuation method (CVM), the travel cost method (TCM) and hedonic prices (HP).

\section{Table 4-Ecological lagoon functions, economic goods and services, types of values, and applicable valuation methods}

The fact that lagoons are public goods increases the difficulty of their management and evaluation. In order to set up prices for the supplied services, complex or indirect methods have been successively developed to elicit people's preferences: one distinguishes revealed and stated preferences.

Using revealed preferences methodology, the aim is to recover (or discover) the consumer's preferences and then to use this information to work out money measures of the consumer's welfare change. Revealed preferences stem from different methods. Observed or simulated market prices give direct evaluation whereas travel costs, hedonic property values, net factor income or avoidance expenditures are indirect indicators.

With stated preferences methods, information comes from what the consumer states when directly asked to express the value he gives to the public good or service. This is the principle of the contingent valuation method and its extension, choice experiments: for a carefully defined scenario, producers and consumers are directly asked their preferences. Responses may be guided with cards or means of payment, elaborated and presented with much care in order to get relevant answers. 


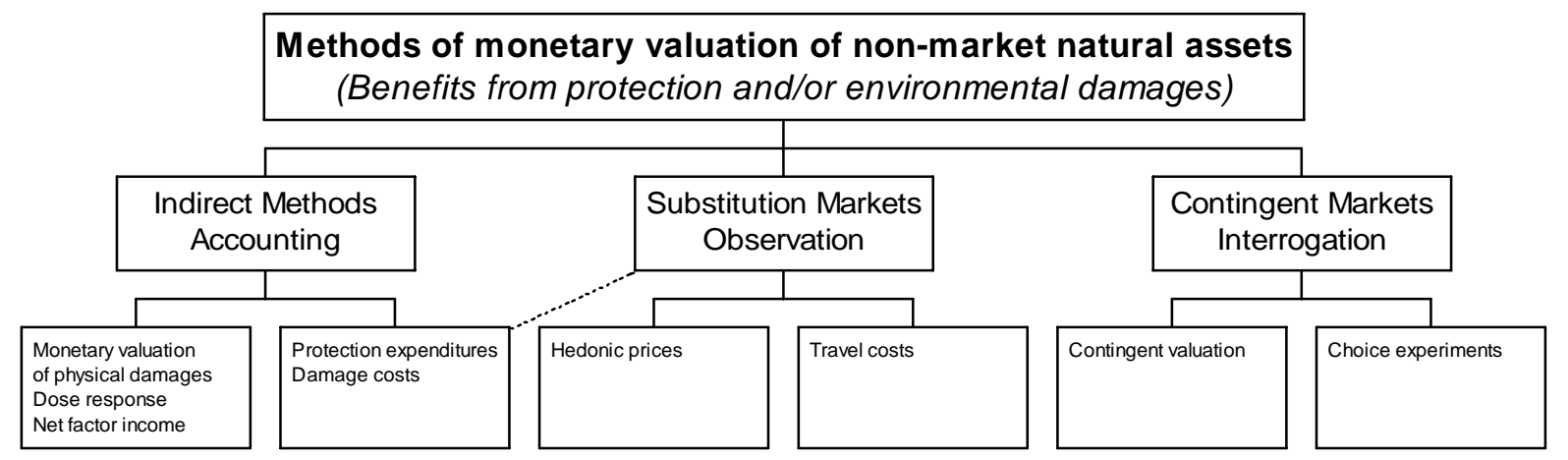

Source: Enjolras and Boisson (2006)

\section{Figure 5 - Methods of monetary valuation of non-market natural assets}

Depending on the context and the kind of value needed, all these methods are currently used. Contingent valuation method (CVM) is one of the most employed one because of its polyvalence, and because it implies non-use values, but the results are very context-related (Bonnieux, 1998). One could think that, as the CVM implies both use and non-use values, it should give higher valuations. This is a point we have noticed, but we have not yet proved. In practice, these techniques require expensive logistics in terms of time and money. Actually, it is necessary to be rigorous to carry out integral surveys for each studied lagoon.

\section{Literature review about the economic valuation of lagoons / Creation of a synthetic database}

For the purpose of our analysis, we need to create a database that includes studies focused on lagoons. This supposes an access to various sources. Our documentation mainly comes from freely available databases on the Internet and from references found in the literature. These sources a very useful tool as noticed for the first time in the literature by McComb et al. (2006).

Since 2002, three main databases refer to studies whose subject is water quality valuation. Thanks to a practical free-access interface, they give the opportunity to select the studies, which are directly in concern with our research.

- The best known is EVRI ${ }^{2}$ (Environmental Valuation Reference Inventory), a Canadian website supported by the Ministries of the Environment of many countries (Canada, USA, France, etc.). When typing "lagoons" in the research box, 8 studies are referred to with a detailed page (context, methodology, main results). When typing "coastal wetlands", about thirty results appear. Then, it is easy to select the studies and look for the proper papers.

- ENVALUE $^{3}$ is another database managed by the New South Wales Department of Environment and Conservation (Australia). Less developed than EVRI, this database lists American, British and Australian studies. The interface is similar. However, lagoons and coastal wetlands are not well referenced.

\footnotetext{
${ }^{2}$ http://www.evri.ca

3 http://www.epa.nsw.gov.au/envalue/
} 
- The Office International de l'Eau (International Office for Water) offers a French database exclusively dedicated to the economic valuation of water. The research facilities permitted us to identify ten studies whose main weakness is that they are not electronically available.

Among the other sources, we use some of the U.S. studies referenced by Woodward and Wui (2001) in their meta-analysis. We also select many Italian studies from the Fondazione Eni Enrico Mattei focused on the lagoon of Venice.

We finally include in our analysis 32 studies representing 67 observations directly usable. The following Table 6 displays their origins.

\begin{tabular}{|c|c|c|c|c|c|}
\hline Number & Authors & Source $^{\mathrm{a}}$ & Year & Country & Studies $^{b}$ \\
\hline 1 & Alberini A., Rosato P. et al. & Journal Article (JEPM) & 2004 & Italy & 1 \\
\hline 2 & Alberini A. and Zannata V. & Journal Article (EE) & 2005 & Italy & 2 \\
\hline 3 & Amasher G.S., Brazee J.W. et al. & Report & 1989 & USA & 6 \\
\hline 4 & Barbier E.B. and Strand I. & Journal Article (ERE) & 1998 & Mexico & 1 \\
\hline 5 & Batie S.S. and Wilson J.R. & Journal Article (SJAE) & 1978 & USA & 7 \\
\hline 6 & Bell F.W. 1989 & Working Paper & 1989 & USA & 1 \\
\hline 7 & Bell F.W. 1997 & Journal Article (EE) & 1997 & USA & 2 \\
\hline 8 & Bergstrom J.C., Stoll J.R. et al. & Journal Article (EE) & 1990 & USA & 1 \\
\hline 9 & Boisson J.-M. and Rudloff M.-A. & Working Paper & 1998 & France & 1 \\
\hline 10 & Breaux A., Farber S. et al. & Journal Article (JEM) & 1995 & USA & 3 \\
\hline 11 & Cangelosi A., Wiher R. et al. & Report & 2001 & USA & 1 \\
\hline 12 & Chabreck R.H. & Book Chapter & 1979 & USA & 2 \\
\hline 13 & Costanza R., Farber S.C. et al. & Journal Article (EE) & 1989 & USA & 4 \\
\hline 14 & Dabat M.-H. and Rudloff M.-A. & Book Chapter & 1999 & France & 1 \\
\hline 15 & De Zoysa A.D.N. & PhD Dissertation & 1995 & USA & 2 \\
\hline 16 & Dillman B.L., Beran L.J. et al. & Report & 1993 & USA & 1 \\
\hline 17 & Earnhart D. & Journal Article (LE) & 2001 & USA & 4 \\
\hline 18 & Farber S.C. 1987 & Journal Article (JEEM) & 1987 & USA & 1 \\
\hline 19 & Farber S.C. 1988 & Journal Article (JEM) & 1988 & USA & 2 \\
\hline 20 & Farber S.C. 1996 & Journal Article (CEP) & 1996 & USA & 5 \\
\hline 21 & Farber S.C. and Costanza R. & Journal Article (JEM) & 1987 & USA & 2 \\
\hline 22 & Folke C. & Book Chapter & 1991 & USA & 1 \\
\hline 23 & Gren I.-M., Folke C. et al. & Journal Article (ERE) & 1994 & USA & 3 \\
\hline 24 & Joworski E. and Raphel C.N. & Working Paper & 1978 & USA & 2 \\
\hline 25 & Kaoru Y. & Journal Article (ERE) & 1993 & USA & 1 \\
\hline 26 & Lynne G.D., Conroy P. et al. & Journal Article (JEEM) & 1981 & USA & 1 \\
\hline 27 & Morton R.M. & Journal Article (MB) & 1990 & Australia & 1 \\
\hline 28 & Nunes P.A.L., Rossetto L. et al. & Journal Article (JMS) & 2004 & Italy & 2 \\
\hline 29 & Rudloff M.-A. & PhD Dissertation & 1992 & France & 2 \\
\hline 30 & Shabman L.A. and Batie S.S. & Journal Article (MRE) & 1987 & USA & 1 \\
\hline 31 & Signorello G. & Book Chapter & 1999 & Italy & 1 \\
\hline 32 & Zanatta V., Alberini A. et al. & Working Paper & 2004 & Italy & 2 \\
\hline
\end{tabular}

a Abbreviations: CEP Contemporary Economic Policy; EE Ecological Economics; ERE Environmental and Resource Economics; JEEM Journal of Environmental Economics and Management; JEM Journal of Environmental Management; JEPM Journal of Environmental Planning and Management; JMS Journal of Marine Systems; LE Land Economics; MB Marine Biology; MRE Marine Resource Economics; SJAE Southern Journal of Agricultural Economics

$\underline{b}$ Number of observations taken from each study

Table 6 - Synthetic presentation of the studies included in the meta-analysis

\footnotetext{
${ }^{4}$ http://scripts.oieau.fr/base dommages/
} 
As noticed in the former table, all studies come from developed countries. This allows founding the analysis on a set of similar purchasing power parities and attitudes towards the environment. Figures 7 indicates the repartition and shows that U.S. studies are predominant.

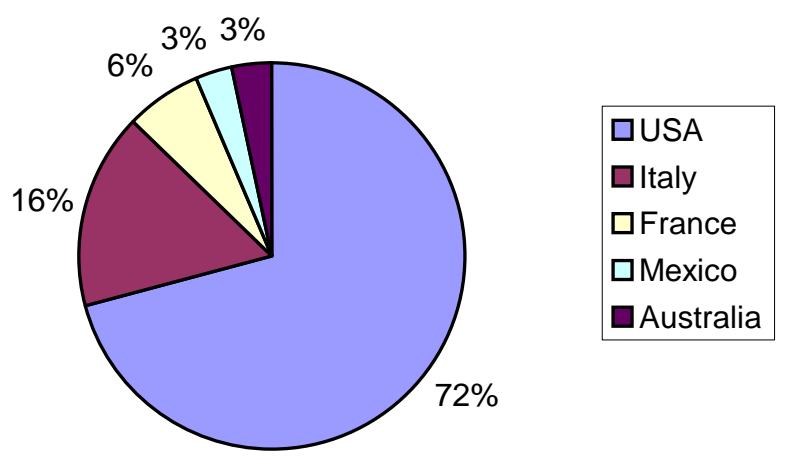

Figure 7 - Geographical origin of the studies

For a better knowledge of the studies lagoons, we propose a wide analytic grid organised according to different significant items for simplicity of use. The items come from our research on lagoon specificities and the usual characteristics of meta-analysis. In addition to Brouwer et al. (1999) and Woodward and Wui (2001) who respectively focus on the original surveys methodologies and the activities in situ, we prefer a more exhaustive approach. We include the two former aspects and we add socio-economic variables and threats indicators. They are as exhaustive as possible in order to preserve the capacity to select the more significant ones. Hoehn (2006) recently emphasized the necessity of a strict choice of pertinent variables for a meta-analysis. He shows that research priority selection is both statistically and economically significant for a meta-analytic transfer, as one can easily guess.

Firstly, in order to classify the studies, we write down their title and aim. Then, we look at the intrinsic characteristics of the site: surface, rural or urban environment and we try to collect some socio-economic variables, which is rather rare and quite difficult. The variables linked to the surveys are one of the specificities of the meta-analytic approach. We look at the year, the survey method (stated or revealed) and the other characteristics of the survey, like the reliability. The lagoons functions are determined according to their specificities: those can be related to ecology, economy, sports and/or culture. These categories are used to classify the lagoons with as much details available as possible. Finally, we point a list of threats.

Like Woodward and Wui (2001) or Brander et al. (2006), we choose to convert the different measure units in US\$ per acre. The US Dollar is taken as reference because most of the studies are American. The conversion into US Dollar of the different studies value is obtained providing some precautions summarized by Ready and Navrud (2006). Converting the currency is not enough because it is necessary to take into account the differences in income. We also take into account the inflation and the purchasing-power-parity with the official indicators of the Organisation for Economic Cooperation and Development ${ }^{5}$ (OECD). However, it is difficult to take into account the cultural and contextual effects of the measures, which is a source of bias. Ready and Navrud (2006) also precise that these challenges in international benefit transfer are not that different from those encountered in transfers between regions within a country. So, transfer errors seem to be comparable to those seen in intra-country transfers.

\footnotetext{
${ }^{5}$ Data available at: $\underline{\text { http://www.oecd.org/document/15/0,2340,en_2825_293564_1873295_1_ } 1 \_1 \_1,00 . h t m l}$
} 
Standardizing wetland values per person was not possible due to the numerous studies with revealed preferences. However, values per person could be easily converted into values per acre given information on the wetland area and the relevant population. This format is also more practical to use.

We expose the detail of the meta-analytic grid in the two following pages (Table 8).

\begin{tabular}{|c|c|c|c|}
\hline \multicolumn{4}{|c|}{ Table 8 - Full meta-analytic grid } \\
\hline Type & Details & Variable & Variable description \\
\hline \multirow{2}{*}{\multicolumn{2}{|c|}{ Source }} & Source & For information \\
\hline & & Publication & $1=$ Published $\mid 0=$ Not published \\
\hline \multirow{5}{*}{\multicolumn{2}{|c|}{ Site }} & USA & $1=$ USA $\mid 0=$ Other country \\
\hline & & Surface of the lagoon & In acres $\mid 1$ acre $=0,405$ ha $\mid 1 \mathrm{ha}=2,471$ acres \\
\hline & & Rural / Urban & $1=$ Rural $\mid 0=$ Urban \\
\hline & & Coastal & $1=$ Coastal site $\mid 0=$ Other \\
\hline & & Substitutes near the lagoon & $1=$ Yes $\mid 0=$ No \\
\hline \multirow{31}{*}{ Survey } & Year & Year & In years $(0=1960)$ \\
\hline & Aim & Improvement & $1=$ Improvement $\mid 0=$ Preservation, status-quo \\
\hline & Study & Primary / Secondary & $1=$ Primary $\mid 0=$ Secondary \\
\hline & \multirow{2}{*}{ Units } & Initial unit & Name and year of national currency \\
\hline & & Adjustment coefficient & Conversion in 07/2005 US\$ \\
\hline & \multirow{5}{*}{ Payment } & $>$ Total payment & In national currency \\
\hline & & > Payment/person & In national currency \\
\hline & & > Payment/household & In national currency \\
\hline & & > Payment/acre & In national currency \\
\hline & & Payment (converted) & In 07/2005 US\$ per acre \\
\hline & \multirow{2}{*}{ Surplus } & Consumer surplus & $1=$ Yes $\mid 0=$ No \\
\hline & & Producer surplus & $1=$ Yes $\mid 0=$ No \\
\hline & \multirow{8}{*}{$\begin{array}{c}\text { Estimation } \\
\text { method }\end{array}$} & Estimation method & $1=$ Stated preferences $\mid 0=$ Revealed preferences \\
\hline & & $>$ Choice Experiments & $1=$ Yes $\mid 0=$ No \\
\hline & & > Contingent Valuation & $1=$ Yes $\mid 0=$ No \\
\hline & & $>$ Hedonic Prices & $1=$ Yes $\mid 0=$ No \\
\hline & & > Market Value & $1=$ Yes $\mid 0=$ No \\
\hline & & $>$ Net Factor Income & $1=$ Yes $\mid 0=$ No \\
\hline & & $>$ Replacement Costs & $1=$ Yes $\mid 0=$ No \\
\hline & & > Travel Costs & $1=$ Yes $\mid 0=$ No \\
\hline & \multirow{5}{*}{$\begin{array}{l}\text { Survey } \\
\text { method }\end{array}$} & Survey method & 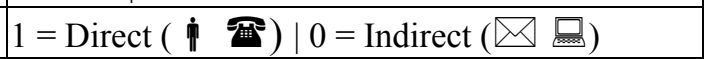 \\
\hline & & $>$ Expertises & $1=$ Yes $\mid 0=$ No \\
\hline & & $>$ Interview & $1=$ Yes $\mid 0=$ No \\
\hline & & $>$ Letter / Internet & $1=$ Yes $\mid 0=$ No \\
\hline & & \begin{tabular}{|l|} 
Telephone \\
\end{tabular} & $1=$ Yes $\mid 0=$ No \\
\hline & \multirow{3}{*}{$\begin{array}{c}\text { Revelation } \\
\text { method }\end{array}$} & Dichotomic & $1=$ Yes $\mid 0=$ No \\
\hline & & Iterative & $1=$ Yes $\mid 0=$ No \\
\hline & & Open & $1=$ Yes $\mid 0=$ No \\
\hline & \multirow{3}{*}{$\begin{array}{c}\text { Payment } \\
\text { vehicle }\end{array}$} & Price increase & $1=$ Yes $\mid 0=$ No \\
\hline & & Income tax & $1=$ Yes $\mid 0=$ No \\
\hline & & Tax per visit & $1=$ Yes $\mid 0=$ No \\
\hline
\end{tabular}


$\underline{\text { Table } 8 \text { - Full meta-analytic grid (continued) }}$

\begin{tabular}{|c|c|c|c|}
\hline Type & Details & Variable & Variable description \\
\hline \multirow{4}{*}{ Survey } & \multirow{4}{*}{ Reliability } & General reliability & $1=$ Yes $\mid 0=$ No \\
\hline & & $>$ Data reliability & $1=$ Yes $\mid 0=$ No \\
\hline & & > Interpretation reliability & $1=$ Yes $\mid 0=$ No \\
\hline & & $>$ Method reliability & $1=$ Yes $\mid 0=$ No \\
\hline \multirow{7}{*}{\multicolumn{2}{|c|}{$\begin{array}{l}\text { Socio-economic } \\
\text { variables }\end{array}$}} & Affected population & Number \\
\hline & & Household size & Number \\
\hline & & Mean age & Years \\
\hline & & Mean income / household & Number \\
\hline & & Number of children / household & Number \\
\hline & & Sex & Share of male \\
\hline & & Year of studies & Number \\
\hline \multirow{25}{*}{$\begin{array}{l}\text { Lagoon } \\
\text { functions }\end{array}$} & \multirow{6}{*}{ Ecological } & Ecosystem & $1=$ Yes $\mid 0=$ No \\
\hline & & Flood / Storm regulation & $1=$ Yes $\mid 0=$ No \\
\hline & & Natural reserve & $1=$ Yes $\mid 0=$ No \\
\hline & & Purification & $1=$ Yes $\mid 0=$ No \\
\hline & & Reserve & $1=$ Yes $\mid 0=$ No \\
\hline & & Storage & $1=$ Yes $\mid 0=$ No \\
\hline & \multirow{9}{*}{ Economic } & Activities depending on the lagoon & $1=$ Yes $\mid 0=$ No \\
\hline & & $>$ Commercial fishing & $1=$ Yes $\mid 0=$ No \\
\hline & & $>$ Fish farming & $1=$ Yes $\mid 0=$ No \\
\hline & & $>$ Shellfarming & $1=$ Yes $\mid 0=$ No \\
\hline & & $>$ Shellfishing & $1=$ Yes $\mid 0=$ No \\
\hline & & Activities near the lagoon & $1=$ Yes $\mid 0=$ No \\
\hline & & > Agriculture & $1=$ Yes $\mid 0=$ No \\
\hline & & $>$ Industry & $1=$ Yes $\mid 0=$ No \\
\hline & & $>$ Thermal baths & $1=$ Yes $\mid 0=$ No \\
\hline & \multirow{10}{*}{$\begin{array}{c}\text { Culture } \\
\text { and } \\
\text { Sports }\end{array}$} & Culture & $1=$ Yes $\mid 0=$ No \\
\hline & & $>$ Aesthetic & $1=$ Yes $\mid 0=$ No \\
\hline & & $>$ Monuments & $1=$ Yes $\mid 0=$ No \\
\hline & & $>$ Species observation & $1=$ Yes $\mid 0=$ No \\
\hline & & Sport & $1=$ Yes $\mid 0=$ No \\
\hline & & $>$ Bathing & $1=$ Yes $\mid 0=$ No \\
\hline & & $>$ Hunting & $1=$ Yes $\mid 0=$ No \\
\hline & & $>$ Fishing & $1=$ Yes $\mid 0=$ No \\
\hline & & $>$ Walking & $1=$ Yes $\mid 0=$ No \\
\hline & & $>$ Water sports & $1=$ Yes $\mid 0=$ No \\
\hline \multirow{9}{*}{ Threats } & Generalities & Threats & $1=$ Yes $\mid 0=$ No \\
\hline & \multirow{5}{*}{ Anthropic } & $>$ Eutrophication & $1=$ Yes $\mid 0=$ No \\
\hline & & $>$ Salinity & $1=$ Yes $\mid 0=$ No \\
\hline & & $>$ Urbanisation & $1=$ Yes $\mid 0=$ No \\
\hline & & > Use conflicts & $1=$ Yes $\mid 0=$ No \\
\hline & & $>$ Water pollution | Rejections & $1=$ Yes $\mid 0=$ No \\
\hline & \multirow{3}{*}{ Natural } & $>$ Erosion & $1=$ Yes $\mid 0=$ No \\
\hline & & $>$ Filling & $1=$ Yes $\mid 0=$ No \\
\hline & & $>$ Water renewal & $1=$ Yes $\mid 0=$ No \\
\hline
\end{tabular}


Figure 9 shows the diversity of evaluation methods included in the meta-analysis. Contingent valuation and choice experiments are not the majority contrary to most of the existing metaanalytic studies by Brouwer et al. (1999) or Woodward and Wui (2001).

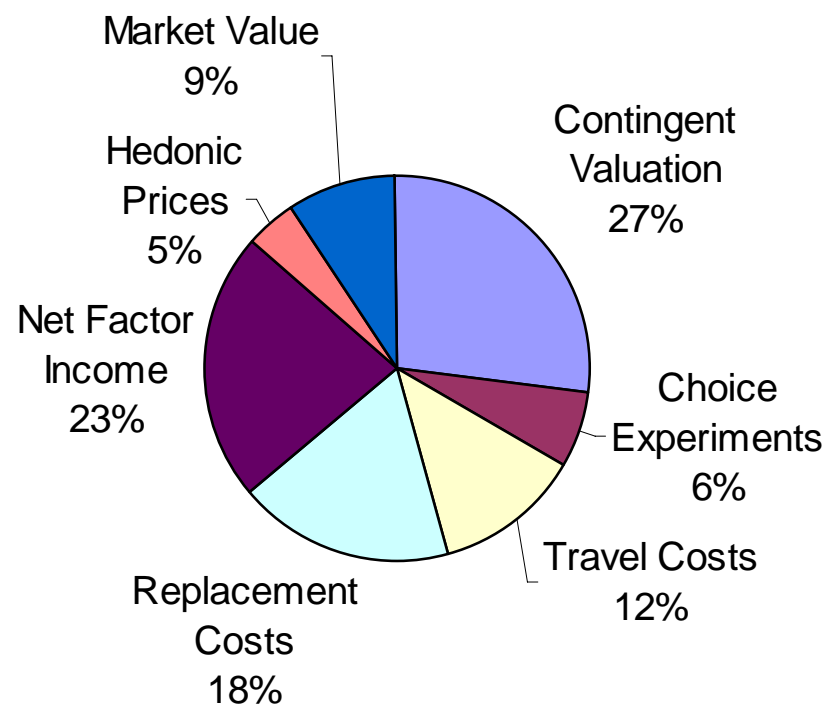

\section{Figure 9-Valuation methods}

The lagoon services, which are mentioned and taken into account in our sample are detailed in the following graph. One can notice the importance of biodiversity and fishing.

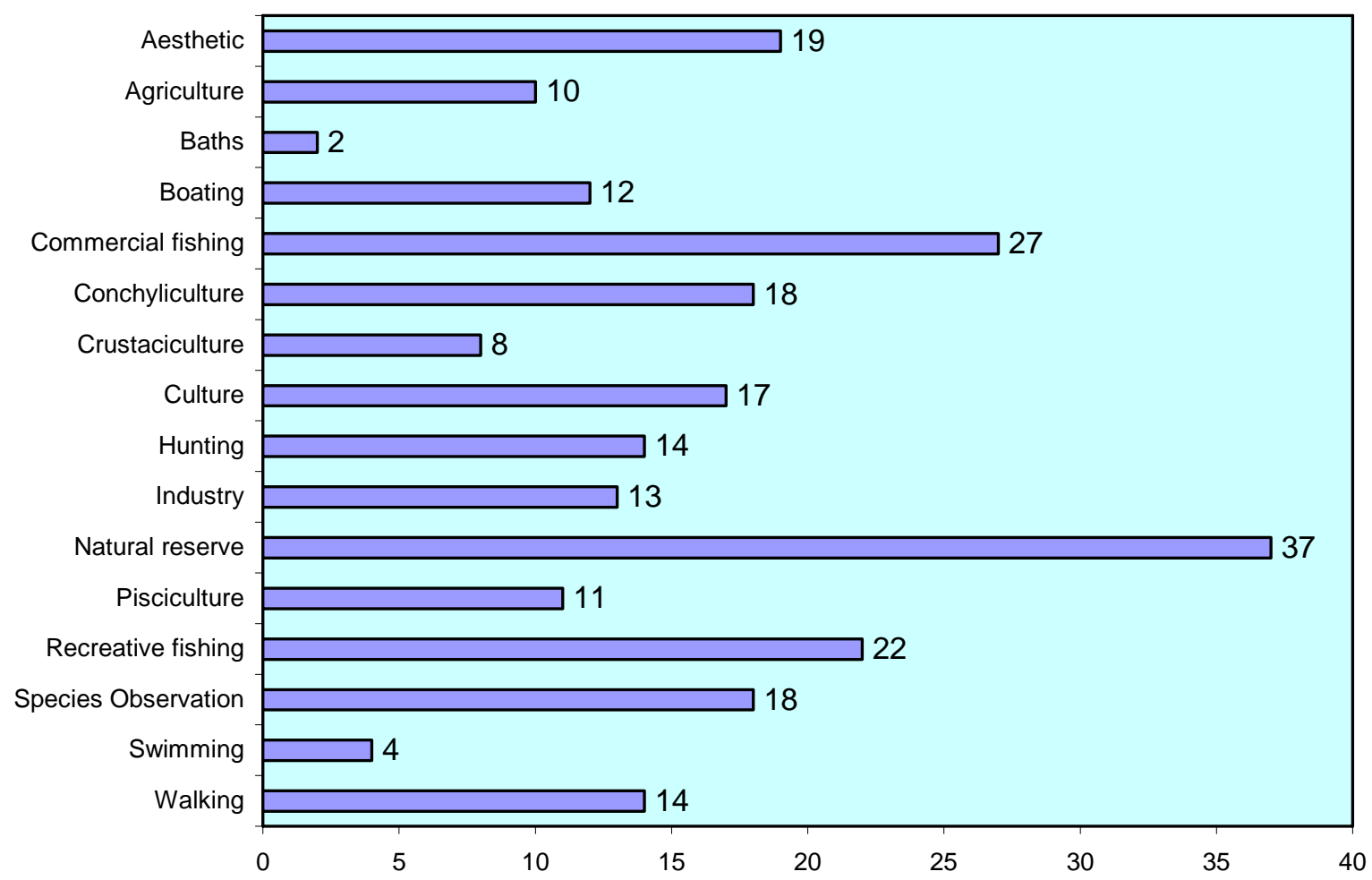

Figure 10 - Number of observations for each lagoon service 


\begin{tabular}{|c|c|c|c|c|c|c|}
\hline Category & Main variables & $\begin{array}{c}\text { Number } \\
\text { of studies }\end{array}$ & $\begin{array}{c}\text { Mean price } \\
\text { (in US\$ par } \\
\text { acre) }\end{array}$ & Std Error & Min & Max \\
\hline In general & All lagoons & 67 & 62,886 & 218,079 & 0.08 & $1,269,374$ \\
\hline \multirow{4}{*}{ Site } & USA & 49 & 75,711 & 250,892 & 0.08 & $1,269,374$ \\
\hline & Rural & 18 & 24,487 & 48,012 & 1.08 & 147,988 \\
\hline & Substitutes & 16 & 179,952 & 335,509 & 11.73 & $1,269,374$ \\
\hline & Improvement & 16 & 77,849 & 167,268 & 13.58 & 627,841 \\
\hline \multirow{2}{*}{ Surplus } & Consumer surplus & 34 & 90,174 & 242,745 & 13.58 & $1,269,374$ \\
\hline & Producer surplus & 10 & 863 & 2,420 & 0.94 & 7,745 \\
\hline \multirow{7}{*}{ Valuation method } & Choice Experiments & 4 & 474,317 & 607,066 & 13.58 & $1,269,374$ \\
\hline & Contingent Valuation & 18 & 63,886 & 90,672 & 14.87 & 147,988 \\
\hline & Hedonic Prices & 3 & 182,287 & 160,437 & 34.65 & 302,188 \\
\hline & \begin{tabular}{|l|} 
Market Value \\
\end{tabular} & 6 & 1,041 & 1,343 & 1.08 & 3,384 \\
\hline & Net Factor Income & 15 & 71,332 & 274,500 & 5.96 & $1,063,587$ \\
\hline & Replacement Costs & 12 & 1,442 & 2,384 & 0.08 & 7,745 \\
\hline & Travel Costs & 8 & 358 & 294 & 11.73 & 723 \\
\hline \multirow{4}{*}{ Revelation method } & Direct survey & 8 & 16,352 & 45,651 & 2.35 & 129,326 \\
\hline & Dichotomic & 13 & 77,402 & 102,591 & 20.42 & 302,188 \\
\hline & Iterative & 2 & 39,855 & 55,754 & 430.77 & 79,279 \\
\hline & Open & 14 & 140,930 & 365,057 & 13.58 & $1,269,374$ \\
\hline \multirow{3}{*}{ Payment vehicle } & Price increase & 6 & 407,569 & 481,661 & 34.65 & $1,269,374$ \\
\hline & Income tax & 6 & 51,544 & 55,091 & 20.42 & 129,326 \\
\hline & Tax per visit & 11 & 27,209 & 50,058 & 13.58 & 147,988 \\
\hline \multirow{2}{*}{ Study Reliability } & Publication & 47 & 59,714 & 209,740 & 0.08 & $1,269,374$ \\
\hline & General reliability $^{6}$ & 48 & 61,671 & 207,625 & 0.94 & $1,269,374$ \\
\hline \multirow{5}{*}{ Lagoon functions } & Ecosystem & 55 & 70,356 & 237,662 & 1.08 & $1,269,374$ \\
\hline & Flood / Storm regulation & 9 & 272,198 & 431,545 & 0.94 & $1,269,374$ \\
\hline & \begin{tabular}{|l|} 
Natural reserve \\
\end{tabular} & 37 & 78,967 & 234,348 & 2.35 & $1,269,374$ \\
\hline & Purification & 10 & 15,232 & 34,837 & 0.08 & 111,253 \\
\hline & Storage & 20 & 30,826 & 48,845 & 2.39 & 147,988 \\
\hline \multirow{4}{*}{ Activities in the lagoon } & Commercial fishing & 27 & 41,488 & 204,375 & 5.97 & $1,063,587$ \\
\hline & Fish farming & 11 & 1,388 & 1,847 & 13.58 & 6,106 \\
\hline & \begin{tabular}{|l|} 
Shellfarming \\
\end{tabular} & 18 & 353 & 457 & 5.97 & 1,340 \\
\hline & Shellfishing & 8 & 431 & 590 & 1.08 & 1,340 \\
\hline Activities near the lagoon & Agriculture, industry & 18 & 27,144 & 44,979 & 13.58 & 147,988 \\
\hline \multirow{10}{*}{ Culture and sports } & Culture & 20 & 145,845 & 306,285 & 14.87 & $1,269,374$ \\
\hline & \begin{tabular}{|l} 
Aesthetic \\
\end{tabular} & 19 & 153,518 & 312,697 & 14.87 & $1,269,374$ \\
\hline & $>$ Monuments & 17 & 171,481 & 326,718 & 14.87 & $1,269,374$ \\
\hline & $>$ Species observation & 18 & 154,863 & 321,705 & 14.87 & $1,269,374$ \\
\hline & Sport & 30 & 87,508 & 258,969 & 2.35 & $1,269,374$ \\
\hline & $>$ Bathing & 4 & 33,077 & 64,169 & 20.42 & 129,326 \\
\hline & $>$ Hunting & 14 & 3,264 & 9,109 & 2.35 & 34,404 \\
\hline & $>$ Recreational fishing & 22 & 2,344 & 7,291 & 11.73 & 34,404 \\
\hline & $>$ Walking & 14 & 177,813 & 363,238 & 14.87 & $1,269,374$ \\
\hline & $>$ Water sports & 12 & 206,934 & 386,592 & 14.87 & $1,269,374$ \\
\hline Threats & Threats & 23 & 120,130 & 290,444 & 13.58 & $1,269,374$ \\
\hline
\end{tabular}

\section{Table 11 - Summary statistics of the main variables}

\footnotetext{
${ }^{6}$ According to the authors of the original studies.
} 
Table 11 presents a present a breakdown of lagoon values per acre. The range of values is an indicator of the explanatory power of each of the lagoon characteristics or functions. We can also view the influence of the different valuation methods:

- The location is the first indicator: U.S. lagoons are more valorised than lagoons located all over the world. Brouwer et al. (1999) assert this result is also an indicator of people's capacity to pay. It could also be explained by the fact that U.S. respondents are more used to evaluate things in terms of money. Rural lagoons present a small value compared to urban one.

- Reasoning in terms of consumer surplus generates a large positive effect compared to a value explained in terms of producer surplus. Rudloff (1997) explained this difference with a Contingent Valuation study. For the preservation of the Thau Lagoon (Etang de Thau) located in the South of France, the consumer felt more concerned and then exhibited a higher willingness to pay than the producers of the lagoon.

- Looking at the valuation method gives unsurprising results. Choice Experiments and Contingent Valuation are supposed to capture both use and non-use values, so mean value is normally higher in these cases. Hedonic Prices studies mainly refer to a change of land and/or buildings value, so the elicitation scale is very often one of the highest. On the contrary, Travel Costs Method only yields smaller values.

- The questionnaires form (in the case of stated preferences) allows showing that open answers are higher than dichotomous and iterative one. This kind of effect is not negligible.

- Among lagoon functions, flood and storm regulation have a great influence on the value because this role considerably preserves the (urban) environment. The existence of natural species is also a net factor. On the contrary, the purification role of the lagoons is not well valuated.

- Commercial fishing gives a great value to the lagoons compared to shellfishing and shellfarming, which is not obvious to interpret. Potentially dangerous activities for the lagoons like agriculture or industry contribute to minimize the value compared to the mean. Culture is also very well valued compared to sports and recreation activities. This result could be explained by the competition between the sea and the lagoon, with is intense for bathing or water sports.

- Finally, identified threats double the average value of lagoons.

All the former results allow to better understanding the main determinants of lagoons value. They also highlight our reasoning for the estimation of a meta-analytic function dedicated to lagoons.

\section{Estimation of a multivariate meta-analytic function dedicated to lagoons}

A meta-analysis is a particular method whose aim is, as we have mentioned previously, to capture existing statistical relationships between the benefits measure (WTP, for example) and quantifiable characteristics of different studies on the subject. Close to traditional variables (socio-economic, characteristics of the studied object...), the meta-analysis takes also into account methodological variables (valuation method, for example) that consider the surveys' specificities. Thus, this approach supposes the studies' characteristics significantly influence the surveys' results. 
Consequently, the transfer function takes the following form:

$$
\ln \left(V_{S}\right)=\alpha_{0}+\sum_{i} \alpha_{i} X_{i S}+\sum_{j} \alpha_{j} Y_{j S}+\sum_{k} \alpha_{k} Z_{k S}+u_{S}
$$

Where: $V_{S}$ is the matrix of values found in the study sites; $\alpha_{0}, \alpha_{i}, \alpha_{j}$ and $\alpha_{k}$ are the estimated parameters respectively associated to the intercept of the model, the characteristics of the studied object noted $\mathrm{X}_{\mathrm{iS}}$, the characteristics of the surveyed population $\mathrm{Y}_{\mathrm{jS}}$ and the study characteristics $Z_{\mathrm{kS}}$; $\mathrm{u}_{\mathrm{S}}$ is the error rate.

The estimation of the function relies on the use of the various studies taken from literature. Each study must be read and analysed in details so that information is sufficient to estimate a multivariate meta-analytic function. One must take care of the correct interpretation of the original results in order to compile a correct database. Then, the procedure consists in estimating various econometric models using our database. As we have a great number of variables, we decided to define five main categories: site, survey, socio-economic variables, lagoon functions and threats. For an easy-to-use estimation, lots of variables take the form of dummies, as shown in Table 8, and we made variable groupings. For example, the different valuation methods can be dispatched in two types, whether the value is obtained with stated or revealed preferences.

Then, we estimate a global econometric model. The dependant variable, i.e. the one to be determined, is specified as the annual value for water in 2005 US\$ for an acre of lagoon. The function is estimated with Generalized Least Squares. Regression variables include lagoon characteristics, activities linked to water quality and threats on lagoons. Eliminating correlated variables and performing a backward stepwise regression leads to the selection of most representative variables. This procedure does not judge before the significance of each variable but is useful to estimate a robust model. We can parameterise it in relation with the considered specificities of the studied lagoon.

The final model takes into account 17 variables plus the intercept. The dependant variable, i.e. the value given to water (in US\$ per acre), and the surface are expressed in logarithm form because of their excessive variance. All the other variables, excepted the year of the study, are dummy, which facilitates the application of the estimated equation to any site.

The determination coefficient of our model is equal to: $\mathrm{R}^{2}=0,649$. It means that our model is correctly adjusted by the selected variables. To confirm this validation, we apply standard tests. 
The estimation gives the following model:

\begin{tabular}{|c|c|c|c|c|c|}
\hline Variable $^{b}$ & Description & Coefficient & Std Error & $\mathbf{t}$ & $\mathbf{P}>|\mathbf{t}|$ \\
\hline Intercept & The intercept of the econometric model & $7.081 * * *$ & 2.407 & 2.94 & 0.005 \\
\hline \multicolumn{6}{|c|}{ Lagoon characteristics } \\
\hline Year & Year of the study (Reference=1969) & $0.181 * * *$ & 0.052 & 3.49 & 0.001 \\
\hline Surface & Logarithm of the lagoon surface (in Acres) & $-0.324 * *$ & 0.132 & -2.45 & 0.018 \\
\hline Rural & Location in a rural area & $1.979 * *$ & 0.871 & 2.27 & 0.028 \\
\hline Substitutes & Substitutes near the lagoon & 1.727 & 1.100 & 1.57 & 0.124 \\
\hline Improve & Policy in vigour to improve water quality & 1.495 & 0.949 & 1.58 & 0.122 \\
\hline \multicolumn{6}{|c|}{ Lagoon functions and uses } \\
\hline Nature & Natural reserve & $2.206^{* *}$ & 0.931 & 2.37 & 0.022 \\
\hline Catastrophe & Protection against floods and storms & 2.065 & 1.377 & 1.50 & 0.141 \\
\hline Culture & Culture and Aesthetic & -1.685 & 1.557 & -1.08 & 0.285 \\
\hline Sport & Sports activities & -1.202 & 0.996 & -1.21 & 0.234 \\
\hline Activity-in & Commercial (shell)fishing and aquaculture & 0.200 & 0.948 & 0.21 & 0.834 \\
\hline Activity-out & Activities near the lagoon (agriculture, industry) & -0.870 & 1.091 & -0.80 & 0.429 \\
\hline \multicolumn{6}{|c|}{ Lagoon threats } \\
\hline Pollution & Pollution crises & $-5.202 * * *$ & 1.366 & -3.81 & 0.000 \\
\hline \multicolumn{6}{|c|}{ Study characteristics } \\
\hline Publication & Published study & $-1.953 *$ & 1.104 & -1.77 & 0.084 \\
\hline Reliability & General reliability of the study & $1.650^{*}$ & 0.979 & 1.68 & 0.099 \\
\hline Stated & Stated preferences & 0.449 & 0.980 & 0.46 & 0.649 \\
\hline PS & Value explained in terms of Producer Surplus & $-4.343 * * *$ & 0.789 & -5.51 & 0.000 \\
\hline Revtax & Income tax for lagoon improvement/restoration & $2.215^{*}$ & 1.323 & 1.67 & 0.100 \\
\hline \multicolumn{6}{|c|}{ ( } \\
\hline $\mathbf{R}^{2}$-adjusted & Determination coefficient & 0.649 & & & \\
\hline $\mathbf{F}(17,48)$ & Fisher test & $10.860 * * *$ & & & \\
\hline Prob > F & Overall validity test (Rejection probability) & 0.000 & & & \\
\hline
\end{tabular}

a OLS results with White-adjusted standard errors. Significance is indicated with ***,** and * for the 1,5 and $10 \%$ respectively.

$\underline{b}$ The lagoon characteristics, function and uses are not strictly non-overlapping variables. In other words, some lagoons provide more than one service and comprise smaller areas of different types. There is also not a one-toone correspondence between an observed value and the use of a specific valuation method. Consequently, there is no need for the omission of one of the categories in order to avoid perfect collinearity.

\section{$\underline{\text { Table } 12 \text { - Meta-analytic function }}{ }^{a}$}

The model is validated by standard econometric tests. All the parameters are heteroscedasticity-robust and the overall validity test confirms their joint existence. 10 variables out of 18 are significant at the $10 \%$ level. The results are similar to Hoehn (2006) in the sense that the empirical analysis shows that the coefficients based on the studies and lagoons characteristics are quite robust. Tests on the residuals confirm the validity of the model. 
As we can see, the coefficients sign and intensity of our estimated functions are very close to the one observed in Table 11. Among the results, we notice the following points:

- The model presents a significant and high intercept.

- We notice that the most significant variables refer to lagoons and study characteristics. This kind of result is not surprising as the first aim of a meta-analysis is to capture these influences. For example, we have noticed in Table 11 the impact of the different valuations methods on price determination, which justifies the introduction of a specific variable.

- Looking at the lagoon characteristics, our study presents similar results compared to the studies by Brouwer et al. (1999) and Woodward and Wui (2001). Coefficients globally move the same way especially the year of reference and the surface. In the first case, we can consider the value increases with time because of an increasing purchasing power in developed countries and a greater sensibility to the environment. The second case is explained by standard economic theory: as the surface increases, the value decreases because the lagoon utility is decreasing. Our study results clearly indicate there is no "return to scale" ${ }^{7}$, i.e. the surface of the lagoon has an negative influence on the payment per acre. This is in contradiction with Woodward and Wui (2001) but can be justifies by our focalisation on lagoons, which are one of the most productive coastal spaces. Figure 13 gives an illustration.

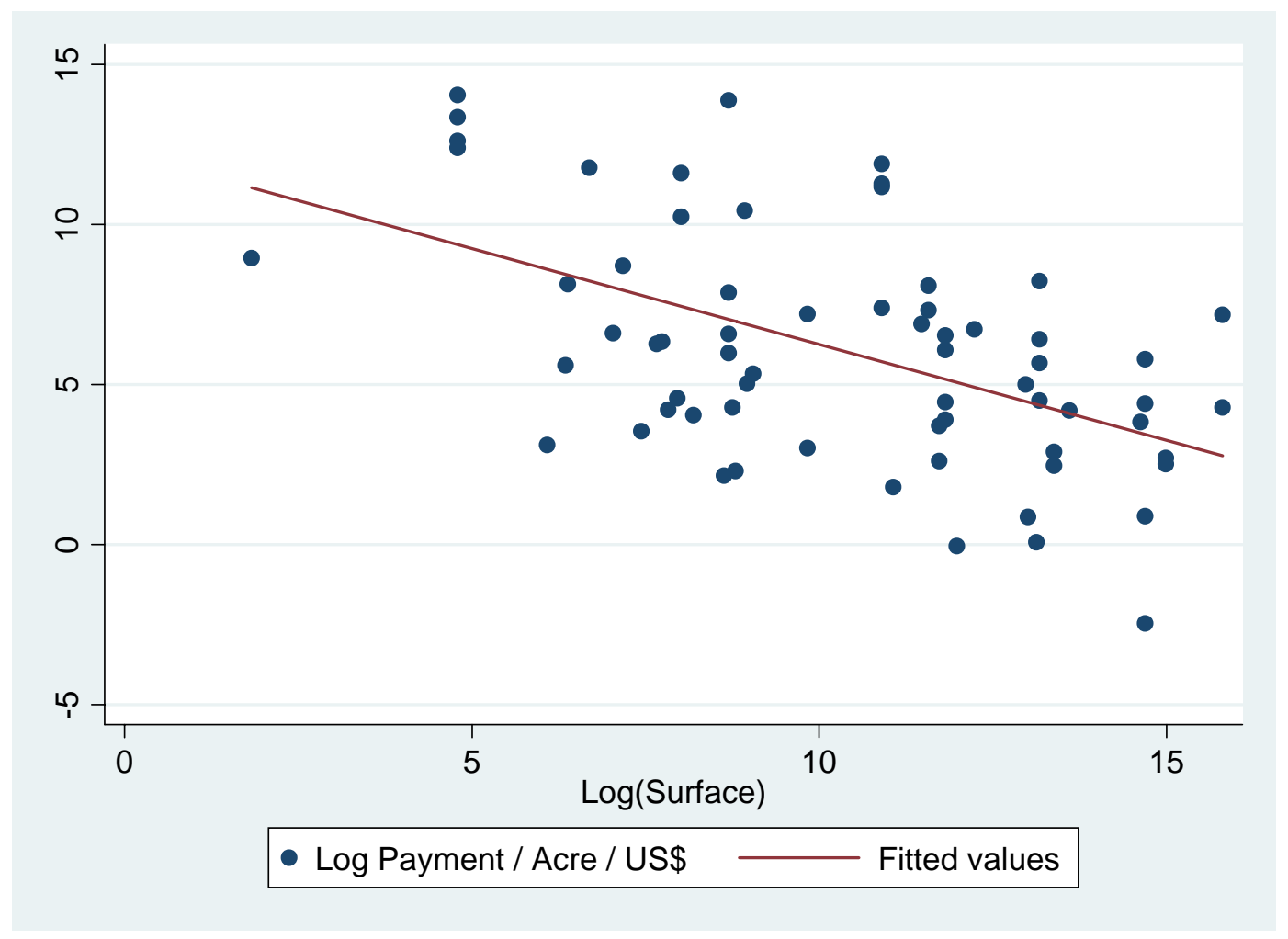

Figure 13 - Relationship between surface and payment per acre

However, this argument is not valid for substitutes because the coefficient is clearly positive. This means for lagoons that the quantity has a higher effect in on value than the quality. Considering rural areas and preservation policies, it seems that preserved lagoons are more valorised. Thus, an easy access does not seem to be a criterion for improving the value.

\footnotetext{
${ }^{7}$ This notion takes into account two phenomena that can neutralize each other: on the one hand, the utility per surface unit decreases as the surface increases while, on the other hand, it can increase because larger lagoons can provide more services that small ones.
} 
- The effects of lagoon functions and uses on the value are surprisingly not really significant. Nevertheless, the coefficients sign and intensity need to be interpreted. The natural functions of the lagoon (habitat for species, protection against floods, livestock for fishing) generate an increase of the value whereas anthropic activities on or near the lagoon (sport, culture, industry, agriculture) have a negative effect. The coefficients seem to be directly linked to the negative externalities of the different functions and activities.

- A confirmation is given by the very negative coefficient associated to threats. Threats mainly come from urbanization, pollution and use conflicts and they logically lead to a diminution of the lagoons values.

- We also introduced in our model exhaustive survey variables that are in majority significant. Stated preference method includes both use and non-use values, which justifies the positive effect. The coefficient is not significant because of the diversity of the methods included in our meta-analysis (cf. Figure 9). Reasoning in terms of producer surplus gives in general lower values than in terms of consumer surplus, which is a sort of "strategic" bias. The producers are directly located on the site whereas many consumers are not, so they minimize their willingness to pay for a restoration or an improvement of the lagoon. The significant coefficient for an income tax indicates people are more willing to pay directly for lagoons improvement/restoration than with an increase in prices, for example.

- Finally, we find a "paradox": published studies show a lower coefficient than the others, whereas rigorous studies present a higher one.

With such a meta-analytic function adapted to lagoons, we can realize valuation transfers on different lagoons. Next section tests our model, provides explanations on the method and some recommendations for a practical use.

\section{Value Transfers}

The use of our meta-analysis is quite simple for a specific lagoon, providing the respect of some rules. Each variable of the function must be parameterised to take into account the studied lagoon's specificities. The result must also be computed taking into account the metric system and the correction of both the purchasing power parity (space correction) and the inflation (time correction). Then, this approach gives the opportunity to get immediate values.

Despite the many improvements in the method and the published studies, the practice of benefits transfer, and in particular its validity tests, reveals transfer error rates that frequently oscillate between 15\% and 75\% for published studies (Rosenberger and Stanley, 2006). This difficulty to obtain a "rigorous" transfer clearly raises the problem of the adaptability of the transfer method to the economic valuation of the lagoons.

Within the framework of the European DITTY project, the French Etang de Thau located near Montpellier had been recently the subject of an in-depth study using different methods, with a special emphasis on a contingent valuation of water quality. Thus, it has been possible to check the model parameterisation. The ratio between the original value as measured in situ and the transferred value with our model is close to 30\%: Rudloff (1997) found a valorisation of water quality equal to 1340 US\$ per acre, and our model estimates a value equal to 917 \$. In this case, the difference is rather small. 
In general, when people are asked to evaluate environmental assets, their individual valuations often vary from 1 to 10 , if not more, because they have neither commercial nor objective references marks and thus give a very wide spectrum of order of magnitude. Therefore, we could legitimately think that a variation of about $50 \%$ constitutes a result to take into account. Accessorily, the estimated total value given by our model seems to correspond, in terms of order of magnitude, to the amounts of public expenditures voted in 2005 by the local authorities to limit eutrophication on the Etang de Thau.

General empiric tests permit to validate our meta-analytic function and can be generalized (Genty, 2005). We use a classic indicator called the "Mean Absolute Percentage Error" (MAPE), which measures the transfer error rate. It is defined as:

$$
M A P E=\left|\frac{V_{\text {observed }}-V_{\text {estimated }}}{V_{\text {observed }}}\right|
$$

Performing the transfer for our sample, we find an average transfer error amount equal to $87 \%$ This is quite a higher forecast error due to a small number of "aberrant" transfer value. However, the median transfer error is equal to $24 \%$, which indicates the first moment is not the only criterion that needs to be taken into account. The distribution of the MAPE indicates that one-fourth of the transfers show errors lower than $10 \%$ and nearly three-fourth of the transfers present errors lower than 50\%.

We can also observe this result graphically (Figure 14). Following Brander et al. (2006), we classified our studies according to the values par acre, in ascending order. Then, we represent both the original logarithms of the values and our model prediction.

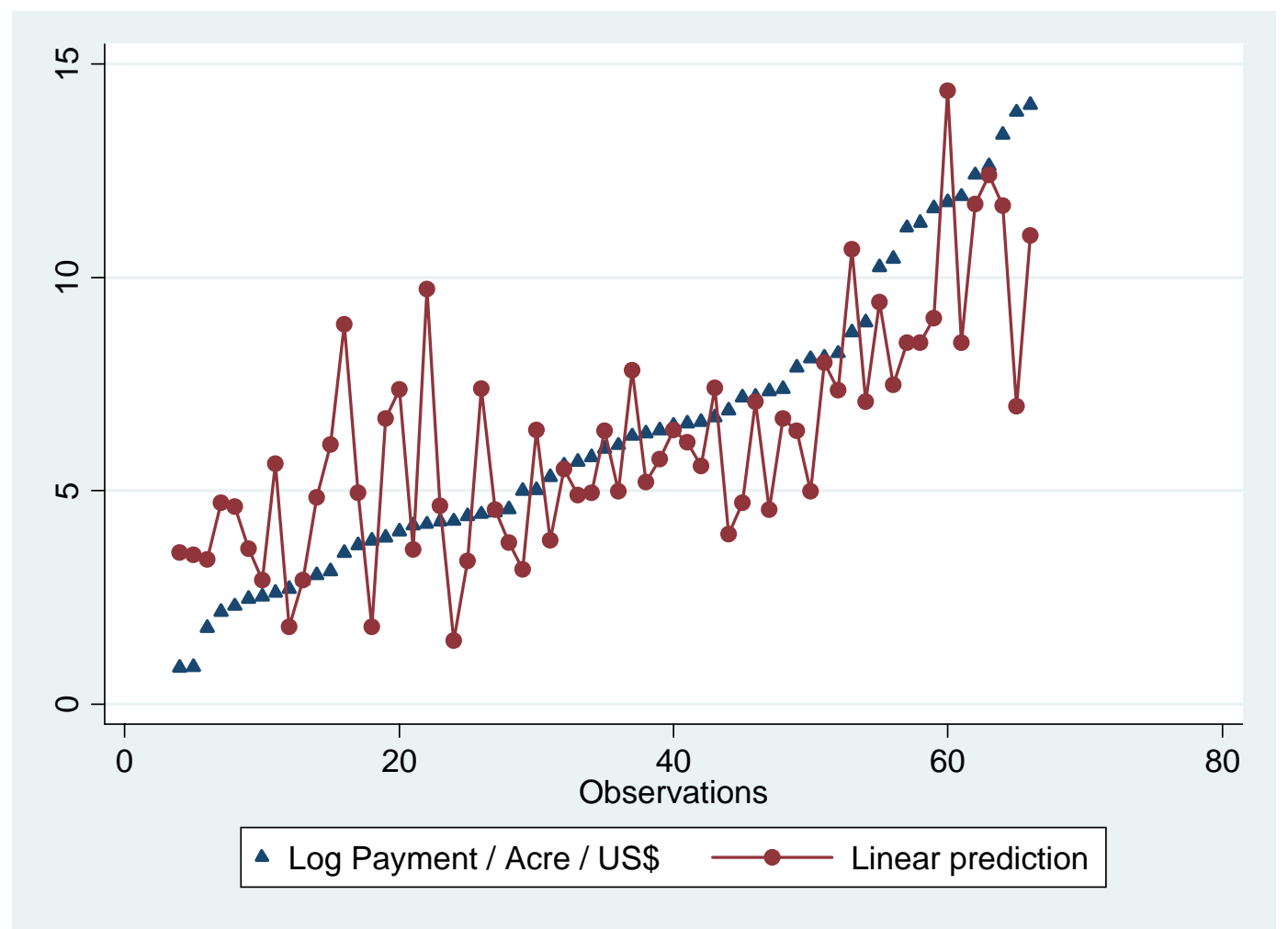

Figure 14 - Transfer efficiency on our sample's studies classed by surface importance 
Figure 14 corresponds to previous results of the literature (Brander et al., 2006). We notice a general over-evaluation for small values and an under-evaluation for large values.

To complete this approach, we use the "Jack-knife" technique, which consists in estimating our model for $n-1$ (66) observations for each of the 67 observations. We obtain 67 equations whose estimated parameters are applied to the omitted observation. The following Figure 15 gives the result. The observations are still classified according to the values par acre, in ascending order.
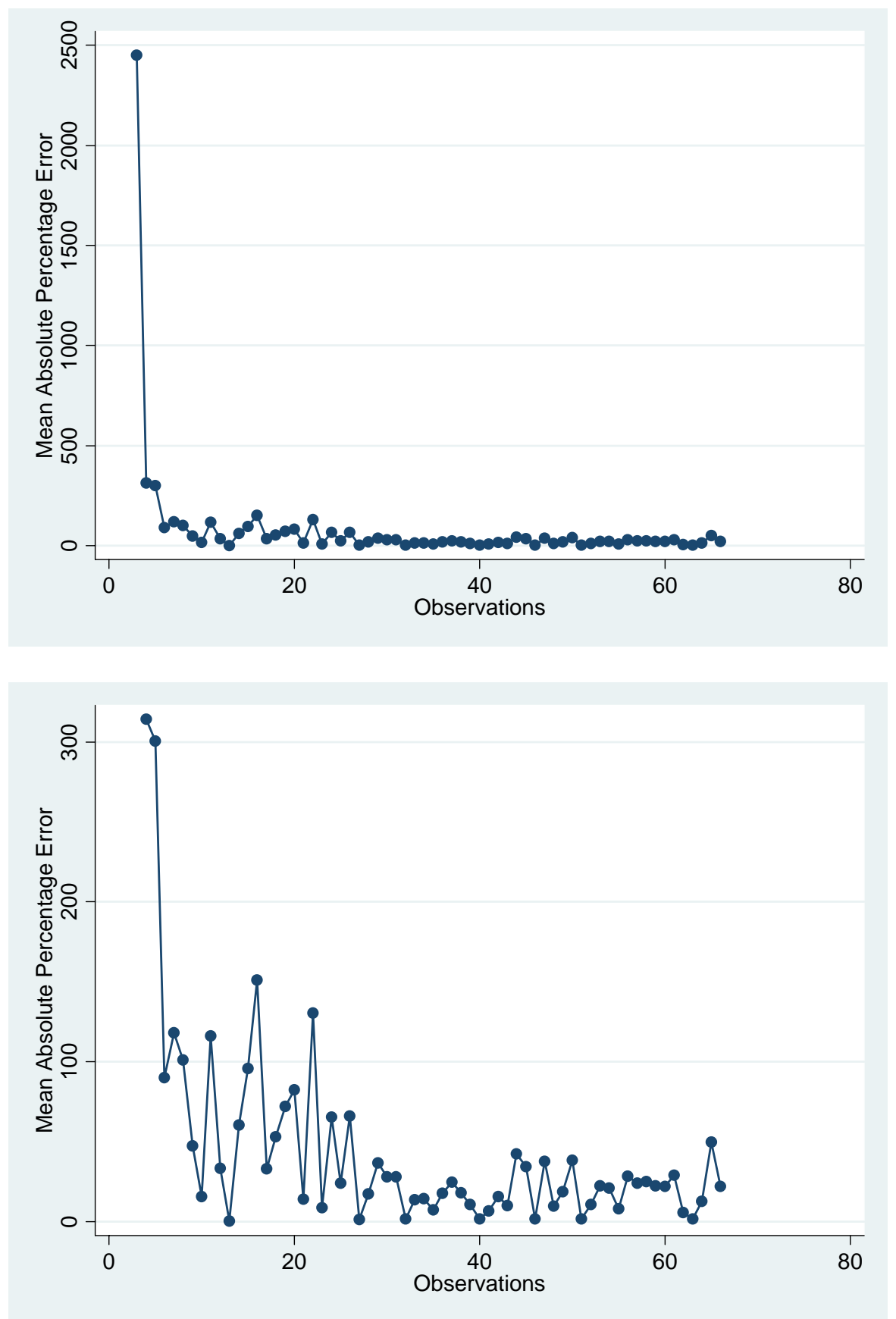

Figure 15 - Observed and predicted lagoon values and transfer errors, ranked in ascending order of observed lagoon value. 
The first figure draws the MAPE for all the observations whereas the second one is a zoom in order to see more precisely the "non-aberrant" results. Using this method, the results are very similar to the former taking into account all observations. There is only a slight degradation of the MAPE because the estimation includes $n-1$ observations. We find an average transfer error amount equal to $95 \%$. This is quite a higher forecast error also due to a small number of "aberrant" transfer value. However, the median transfer error is equal to $27 \%$. We also notice that one-fifth of the transfers show errors lower than $10 \%$ and more than half of the transfers present errors lower than $50 \%$.

The distribution of the MAPE indicates that our model is validated (i.e. the MAPE is under $75 \%$ in $95 \%$ of the cases) provided the transferred values are higher than $2 \$$ par acre. Under this value, the transfer error may be too important as indicated by the graphical observation. This is the only restriction for the use of the model. One should also take care of the units ${ }^{8}$. Provided these recommendations, the model is fully applicable to different lagoons. It may be used as a management indicator for the improvement or the restoration of coastal lagoons located in developed countries.

\section{Concluding remarks}

The methodology we detailed can be considered as a powerful evaluation tool for water in coastal lagoons. Our work contributes to specify water valuation main determinants and their monetary influence in lagoon contexts.

The information contained in our database allowed us to target our evaluations and this work might be expanded in the future. The estimated meta-analysis is globally applicable for any kind of lagoons in industrialized countries. Although our model is validated with average error rates equal to $87 \%$ or $95 \%$ depending on the method, the distribution of the MAPE indicates exploitable results. In particular, our model can be applied only if unitary value exceeds $2 \$$ per acre, which is not a very restrictive condition.

The various pollution sources that threaten lagoon water quality increase the need for quick, cheap and reasonably reliable economic valuations in order to define and implement adequate policies. The meta-analysis is a credible and now widely accepted in the economic literature. Our work may be applied in the context of Northern Mediterranean shores. It should be adapted to apply to Southern shores. Such indexes have already been used as decision tools to define amounts of public expenditures in favour of preserving lagoons environment. This tendency should increase in the future.

\footnotetext{
${ }^{8}$ For Europe, it may be necessary to convert the surface and currency units. 1 acre $=0.405$ hectare. In July 2005, the exchange rate was: 1 US $\$=0.82 €$ after deflation and correction for purchasing-power-parity.
} 


\section{References}

Alberini, A.; Rosato, P.; Longo, A; and Zanatta, V. (2005), "Information and Willingness to Pay in a Contingent Valuation Study: The Value of S. Erasmo in the Lagoon of Venice". Journal of Environmental Planning and Management, Volume 48, no. 2, pp: 155-175.

Alberini, A.; Zanatta, V. and Rosato, P. (2005), "Combining Actual and Contingent Behavior to Estimate the Value of Sports Fishing in the Lagoon of Venice". Ecological Economics (in press).

Amacher, G.S.; Brazee, R.J.; Bulkley, J.W.; Moll, R.A. (1989), "Application of Wetland Valuation Techniques: Examples from Great Lakes Coastal Wetlands". National Technical Information Service, Springfield, 48 pp.

Barbier, E.B. and Strand, I. (1998), "Valuing Mangrove-Fishery Linkages: A Case Study of Campeche, Mexico", Environmental and Resource Economics, 12, Volume 2, no. 2, pp: 151-166.

Batie, S.S. and Wilson, J.R. (1978), "Economic Values Attributable to Virginia's Coastal Wetlands as Inputs in Oyster Production". Southern Journal of Agricultural Economics, 10, pp: 111-118.

Bell, F.W. (1989), "Application of Wetland Evaluation Theory to Florida Fisheries". Tallahassee, Florida: The Florida Sea Grant College.

Bell, F.W. (1997), "The Economic Valuation of Saltwater Marsh Supporting Marine Recreational Fishing in the South-eastern United States". Ecological Economics, 21: 243-254.

Bergstrom, J.C.; Stoll, J.R.; Titre, J.P. and Wright, V.L. (1990), "Economic Value of Wetlands-Based Recreation". Ecological Economics, 2(2): 129-147.

Boisson, J.-M. and Rudloff, M.-A. (1998), "Second-Thoughts on Long Term and Supra Long Term Valuation of Natural Assets in a CVM: Application to the Filling of a Coastal Lagoon". Paper accepted for presentation at the ERE World Congress, Venice, 12 pp.

Bonnieux, F. (1998), "Principe, mise en œuvre et limites de la méthode d'évaluation contingente". Économie publique, 01-1998/1, pp: 47-90.

Brander, L.M.; Florax, J.G.M. and Vermaat, J.E. (2006), "The empirics of wetland valuation: A comprehensive summary and meta-analysis of the literature". Environmental and Resource Economics, 33(2): 223-250.

Breaux, A.; Farber, S. and Day, J. (1995), "Using Natural Coastal Wetlands Systems for Wastewater Treatment: An Economic Benefit Analysis". Journal of Environmental Management, 44: 285-291.

Brouwer, R. and Spaninks F.A. (1999), "The Validity of Environmental Benefits Transfer: Further Empirical Testing". Environmental and Resource Economics, 14: 95-117.

Brouwer, R.; Langford, I.H.; Bateman, I.J. and Turner, R.K. (1999), "A Meta-Analysis of Wetland Contingent Valuation Studies". Regional Environmental Change, 1(1): 47-57.

Brouwer, R. (2000), "Environmental value transfer: state of the art and future prospects". Ecological Economics, 32(1): $137-152$.

Cangelosi, A.; Wiher R.; Taverna J. and Cicero P. (2001), "Wetlands Restoration in Saginaw Bay" in Revealing the Economic Value of Protecting the Great Lakes, National Oceanic and Atmospheric Administration.

Chabreck, R.H. (1979), "Wildlife harvest in wetlands of the United States" in Greeson, P.E.; Clark, J.R. and Clark, J.E. (eds.) Wetland Functions and Values: The State of Our Understanding. Minneapolis, MN: American Water Resources Association, pp: 618-631.

Costanza, R.; Farber, S. C. and Maxwell, J. (1989), "Valuation and management of wetlands ecosystems". Ecological Economics, 1, pp: 335-361. 
Dabat, M.-H. and Rudloff, M.-A. (1999), "La valeur de préservation d'une lagune méditerranéenne menacée de comblement", in Point, P. (dir.), La valeur économique des hydrosystèmes, GIP Hydrosystèmes, Economica, Chap. 6, pp: 107-135.

De Zoyza, A.D.N. (1995), "A Benefit Evaluation of Programs to Enhance Groundwater Quality, Surface Water Quality and Wetland Habitat in NorthWest Ohio". PhD Dissertation, The Ohio State University.

Dillman, B.L., Beran L.J. and Hook D.D. (1993), "Non-market valuation of Freshwater Wetlands: The Francis Biedler Forest". Report 135, South Carolina Water Resources Research Institute, Clemson University, 47 pp.

Earnhart, D. (2001), "Combining revealed and stated preference methods to value environmental amenities at residential locations". Land Economics, 77(1): 12- 29.

Enjolras, G. (2005), "Transfert d'évaluations et valeur économique de l'eau : Application aux lagunes méditerranéennes". Ditty Report (Development of an Information Technology Tool for the Management of European Southern Lagoons), 74 pp.

Enjolras, G. and Boisson, J.-M. (2006), "Analysis of the value of "non market" natural public goods and services, context-related valuations of externalities, and valuations transfer" in Murray, C.N.; Do Chi, T. and Zaldivar-Comenges, J.M. (eds.) Towards Sustainable Management of Southern European Lagoons. Elsevier, Academic Press, forthcoming.

Farber, S. (1987), "The Value of Coastal Wetlands for Protection of Property against Hurricane Wind Damage". Journal of Environmental Economics and Management, 14: 143-151.

Farber, S. (1988), "The Value of Coastal Wetlands for Recreation: an Application of Travel Cost and Contingent Valuation Methodologies". Journal of Environmental Management, 26: 299-312.

Farber, S. (1996), "Welfare Loss of Wetlands Disintegration: A Louisiana Study". Contemporary Economic Policy, 14: 92-106.

Farber, S. and Costanza, R. (1987), "The Economic Value of Wetlands Systems". Journal of Environmental Management, 24: 41-51.

Folke, C. (1991), "The Societal Value of Wetland Life-support" in Folke, C. and Kaberger, T. (eds.) Linking the Natural Environment and the economy: Essays from the Eco-Eco Group. Kluwer Academic Publishers, pp: 141171.

Genty, A. (2005), "Du concept à la fiabilité de la méthode du transfert en économie de l'environnement : un état de l'art". Cahiers d'Economie et Sociologie Rurales, 77: 5-34.

Gren, I.-M.; Folke, C.; Turner, K. and Bateman, I. (1994), "Primary and secondary values of wetland ecosystems". Environmental and Resource Economics, 4: 55-74.

Hoehn, J.P. (2006), "Methods to address selection effects in the meta regression and transfer of ecosystem values". Ecological Economics, 60(2): 389-398.

Joworski, E. and Raphel, C.N. (1978), "Fish, Wildlife and Recreational Values Of Michigan's Coastal Wetlands". Michigan Dept. of Natural Resources, Michigan, 98 pp.

Kaoru Aoru Y. (1993), "Differentiating use and non-use values for coastal pond water quality improvements". Environmental and Resource Economics, 3: 487-494.

Lynne, G.D.; Conroy, P. and Prochaska, F.J. (1981), "Economic Valuation of Marsh Areas for Marine Production Processes". Journal of Environmental Economics and Management, 8: 175-186.

McComb, G.; Lantz, V.; Nash, K. and Rittmaster, R. (2006), "International valuation databases: Overview, methods and operational issues". Ecological Economics, 60(2): 461-472. 
Morton, R.M. (1990), "Community structure, density, and standing crop of fishes in a subtropical Australian mangrove area". Marine Biology, 105: 385-394.

Nunes, P.A.L.D.; Rossetto, L. and de Blaeij, A. (2004), "Measuring the Economic Value of Alternative Clam Fishing Management Practices in the Venice Lagoon: Empirical Examination of an Economic Valuation Study". Journal of Marine Systems, 51: 309-320.

Ready, R. and Navrud S. (2006), "International benefit transfer: Methods and validity tests". Ecological Economics, 60(2): 429-434.

Rosenberger R.S. and Stanley T.D. (2006), "Measurement, generalization, and publication: Sources of error in benefit transfers and their management". Ecological Economics, 60(2): 372-378.

Rudloff, M.A. (1997), "La construction d'un marché contingent. Une application à la qualité de l'eau", PhD Dissertation, Université Montpellier I, 295 p.

Shabman, L.A. and Batie, S.S. (1987), "Mitigating Damages from Coastal Wetland". Marine Resource Economics, 4: 227-248.

Shrestha, R. K. and Loomis J.B. (2003), "Meta-analytic benefit transfer of outdoor recreation economic values: Testing out-of-sample convergent validity". Environmental \& Resource Economics, 25(1): 79-100.

Signorello, G. (1998), "Valuing Bird watching in a Mediterranean Wetland" in Bishop, R.C. and Romano D. (eds.): Environmental Resource Valuation in Italy: Applications of the Contingent Valuation Method, Chapter 9, Kluwer Academic Publishers, pp: 173-192.

Woodward, R. T. and Yong-Suhk W. (2001), "The economic value of wetland. services: a meta-analysis". Ecological Economics, 37: 257-270.

Zanatta, V.; Alberini, A.; Rosato, P. and Longo, A. (2004), "The Value of Recreational Sport Fishing in the Lagoon of Venice: Evidence from actual and hypothetical fishing trips". Paper accepted for presentation at the EAERE (European Association of Environmental and Resource Economists), Annual Meeting. 


\section{Documents de Recherche parus en $2008^{1}$}

DR n²008 - 01_: Geoffroy ENJOLRAS, Robert KAST

«Using Participating and Financial Contracts to Insure Catastrophe Risk : Implications for Crop Risk Management »

DR n²008-02: Cédric WANKO

« Mécanismes Bayésiens incitatifs et Stricte Compétitivité »

DR n²008-03: Cédric WANKO

«Approche Conceptuelle et Algorithmique des Equilibres de Nash Robustes Incitatifs»

DR n²008 - 04 : Denis CLAUDE, Charles FIGUIERES, Mabel TIDBALL

«Short-run stick and long-run carrot policy: the role of initial conditions»

DR n²008 - 05 : Geoffroy ENJOLRAS - Jean-Marie BOISSON

« Valuing lagoons using a meta-analytical approach: Methodological and practical issues »

\footnotetext{
${ }^{1}$ La liste intégrale des Documents de Travail du LAMETA parus depuis 1997 est disponible sur le site internet : http://www.lameta.univ-montp1.fr
} 
Contact :

Stéphane MUSSARD : mussard@lameta.univ-montp1.fr 